\title{
High Dose Tamoxifen and Radiotherapy in Patients with Glioblastoma Multiforme: A Phase IB Study
}

\author{
Thierry Muanza, George Shenouda, Luis Souhami, Richard Leblanc, \\ Gerard Mohr, Robert Corns, Adrian Langleben
}

\begin{abstract}
Purpose: To assess the feasibility and the toxicity of adjuvant high dose tamoxifen (TAM) and postoperative brain irradiation for patients with newly-diagnosed glioblastoma multiforme (GBM). Material and methods: Twelve patients with histopathologically confirmed GBM entered the study. There were nine males and three females, with median age of 48.8 years (range 30-75 years). Karnofsky performance status (KPS) was $60-70 \%$ for four patients and $80-100 \%$ for eight patients. Based on the Radiation Therapy Oncology Group recursive partition analysis, there were three class III patients, six class IV, one class V, and two class VI. Eleven patients underwent partial surgical tumor resection and one patient had a near complete resection. Two weeks post surgery, the patients were started on high dose TAM $\left(120 \mathrm{mg} / \mathrm{m}^{2}\right.$ P.O. BID for three months). Two weeks from date of starting TAM, external beam radiotherapy (RT) was given at a dose of $59.4 \mathrm{~Gy} / 33 \mathrm{qd}$ fractions/6.5 weeks. Patients were assessed weekly for toxicity during treatment. Imaging studies were done at the end of two weeks of TAM, then monthly. Results: Median follow-up was 40 weeks (range 22-84 weeks). In one patient, TAM was associated with significant vomiting, necessitating the TAM dose to be decreased at three weeks and then stopped at two months. One other patient had bilateral deep venous thrombosis after 51/2 weeks on TAM, although the relationship to TAM was not firmly established. There were no radiological responses after two weeks of TAM or at the end of RT. The median time to progression was 17.7 weeks (range 5.1- 43.8 weeks). Median survival time was 33.4 weeks (range 10-79.7). Actuarial survival at 48 and 74 weeks was $40 \%$ and $15 \%$, respectively. Conclusion: Our study shows that adjuvant high dose TAM is feasible and relatively well-tolerated. Furthermore, the combined use of high dose TAM and RT postoperatively was not associated with any significant increase in radiation-induced neurological toxicity. However, high dose TAM does not appear to improve treatment results.
\end{abstract}

RÉSUMÉ: Tamoxifène à haute dose et radiothérapie postopératoire chez des patients atteints de glioblastome multiforme: étude de phase IB. Objectif: Évaluer la praticabilité et la toxicité d'un traitement adjuvant par le tamoxifène à haute dose (TAM) et la radiothérapie cérébrale chez les patients ayant un diagnostic récent de glioblastome multiforme (GBM). Matériel et méthodes: Douze patients ayant un GBM confirmé par anatomopathologie ont été recrutés. Il s'agissait de neuf hommes et trois femmes dont l'âge médian était de 48.8 ans (fourchette de 30 à 75 ans). L'indice de Karnofsky était de 60 à 70\% chez quatre patients et de 80 à 100\% chez huit patients. Selon l'analyse de partition récursive du Radiation Therapy Oncology Group, il y avait trois patients de classe III, six de classe IV, un de classe V et deux de classe VI. Onze patients ont subi une résection chirurgicale partielle et un patient a subi une résection presque complète de la tumeur. Deux semaines après la chirurgie, on a commencé à administrer le TAM à haute dose (120 mg/m2 p.o. b.i.d. pendant trois mois). Deux semaines après le début du TAM, un traitement de radiothérapie externe (RT) a été administré pour une dose totale de 59.4 Gy/33 q.d. fractionnée sur 6.5 semaines. Les patients étaient évalués à chaque semaine quant à la toxicité du traitement. Des études d'imagerie ont été réalisées après deux semaines de TAM et mensuellement par la suite. Résultats: La durée médiane de suivi était de 40 semaines (fourchette de 22 à 84 semaines). Chez un patient, le TAM a été associé à des vomissements importants nécessitant une réduction de la posologie du TAM après trois semaines de traitement et un arrêt après deux mois. Un autre patient a présenté une thrombophlébite profonde bilatérale après $5 \frac{1}{2}$ semaines de TAM, bien que la relation avec le TAM n'ait pas été établie avec certitude. Il n’y a pas eu de réponse radiologique après deux semaines de TAM ou à la fin de la RT. Le temps médian jusqu'à la progression était de 17.7 semaines (fourchette de 5.1 à 43.8 semaines). La survie moyenne était de 33.4 semaines (fourchette de 10 à 79.7 semaines). La survie actuarielle à 48 et 74 semaines était de $40 \%$ et $15 \%$ respectivement. Conclusion: Notre étude démontre qu'un traitement d'appoint par le TAM est faisable et relativement bien toléré. De plus, l'utilisation combinée de doses élevées de TAM et de radiothérapie postopératoire n'était pas associée à une augmentation significative de la toxicité neurologique induite par la radiothérapie. Cependant, le TAM à haute dose ne semble pas améliorer les résultats du traitement.

Can. J. Neurol. Sci. 2000; 27: 302-306

Glioblastoma multiforme (GBM) is the most common primary malignant brain tumor in adults. ${ }^{1,2}$ The median survival time consistently ranges from nine to 12 months and the threeyear survival rate is only $6 \% .^{1}$ Postoperative radiotherapy prolongs median survival time in patients with GBM. However, the response of GBM to standard radiotherapy is limited by its
From the Departments of Oncology, Division of Radiation Oncology (TM, GS, LS, RC), Neuro-Surgery (RL, GM) and Medicine (AL), McGill University, Montreal, Quebec, Canada.

Received January 19, 2000. AcCeptedin Finalform May 23, 2000. Reprint requests to: G. Shenouda. Montreal General Hospital, Division of Radiation Oncology, Suite D5.400, 1650 Cedar Avenue, Montreal, Quebe H3G 1A4, Canada. 
radioresistance. Further increase in radiation dose is limited by the tolerance of surrounding normal brain tissue. ${ }^{1}$

In vitro studies on human glioma cell lines have shown that their growth characteristics can be altered by changing the activity level of the enzyme protein kinase-C (PKC). ${ }^{3}$ Tamoxifen (TAM) has an inhibitory effect on PKC activity. ${ }^{4}$ Experimental laboratory data showed a significant growth inhibition of cultured human glioma cell lines incubated with micromolar $(\mu \mathrm{M})$ concentration of the anti-estrogen TAM. In vivo this concentration was achieved with TAM at doses of 120$150 \mathrm{mg} / \mathrm{m}^{2}$ twice a day (BID). ${ }^{5}$ At $10 \mu \mathrm{M}$ TAM concentrations, the human glioma cell-line U-150GM showed a $61 \%$ growth inhibition as compared to control cultures $(\mathrm{P}<0.05)$. This inhibition was not reversed by estrogen $(100 \mu \mathrm{M})$, suggesting that TAM-induced growth inhibition is independent from estrogen receptor pathways. ${ }^{6}$ Additionally, TAM can cross the blood-brain barrier ${ }^{7}$ and was well-tolerated at doses up to 150 $\mathrm{mg} / \mathrm{m}^{2}$ BID in patients with metastatic malignant melanoma in conjunction with other chemotherapeutic agents. ${ }^{8}$ Furthermore, in vitro studies using TAM and cultured rat glioma C6 cell lines have demonstrated the radiosensitizing potential of TAM. ${ }^{9}$

Phase I/II trials studying the role of high dose TAM as salvage therapy in patients with recurrent high grade gliomas, have not been associated with increased neurotoxicity and demonstrated modest efficacy. ${ }^{5,10,11}$ A phase II trial with high dose TAM performed at McGill University for recurrent high grade glioma showed a $20 \%$ partial response, and $3 \%$ stable disease. ${ }^{12}$ Other authors reported $17 \%$ of partial response and $46 \%$ of stable disease. ${ }^{10}$

This led us to design a phase IB trial to investigate the role of adjuvant high dose TAM concurrently with postoperative radiotherapy. The primary aim of the study was to determine the feasibility and safety of adjuvant high dose TAM and postoperative radiotherapy (RT) in patients with GBM.

\section{Materialand METHODS}

\section{Study}

This phase IB study evaluates the toxicity and feasibility of TAM and RT in the treatment of patients with newly diagnosed GBM. The study was approved by the institutional review board of McGill University.

\section{Patient selection criteria}

Adult patients (age $>18$ years) were included in this study if they fulfilled all the following criteria: histological diagnosis of GBM (WHO grade IV), Karnofsky performance status (KPS) > 60 , no prior radiation therapy to the head and neck region, no prior or concurrent chemotherapy, no prior or concurrent malignancy other than nonmelanomatous skin cancer or carcinoma in situ of the uterine cervix. All patients gave written informed consent.

\section{Pretreatment evaluation}

All patients had a complete history and physical examination including careful assessment of KPS, neurological examination and documentation of current medications. The following pretreatment evaluation tests were performed in all patients: baseline postoperative contrast infused brain computed tomography (CT) scan or magnetic resonance imaging (MRI) one week prior to starting TAM therapy, CBC with differential, SMA-12, electrocardiogram, chest $\mathrm{x}$-ray and baseline ophthalmology consultation. All female patients had a gynecological consultation with special attention to nonhormonal contraceptive measures for women of childbearing potential during and for six months following completion of therapy.

\section{Patient characteristics}

Between October 1996 and May 1998, 12 patients entered the trial. There were three females and nine males with a median age of 48.8 years (range 30-75 years). Based on the Radiation Therapy Oncology Group (RTOG) recursive partition analysis ${ }^{13}$ (RPA) there were three class III, six class IV, one class V, and two class VI patients. KPS was $60-70$ for four patients, 80 for three patients, and 90-100 for five patients. Eleven patients underwent partial resection and one patient had a near complete resection (Table 1). All patients were on steroids prior and during treatment.

The anatomical locations of the lesions were as follows: five frontal, five temporal including one multifocal (temporal and frontal), one parieto-occipital, and one corpus callosum (bilateral).

Table 1: Patient characteristics

Characteristics

Number of patients

Sex:

$$
\text { Male }
$$

9

Female

3

Age:

$\begin{array}{ll}30-49 & 6 \\ 50-69 & 5 \\ \geq 70 & 1\end{array}$

KPS:

$\begin{array}{ll}60 \%-79 \% & 4 \\ 80 \%-89 \% & 3 \\ 90 \%-100 \% & 5\end{array}$

RPA Classes:

III 3

IV 6

$\mathrm{V} 21$

VI 2

Extent of Surgery:

Biopsy 2

Partial Resection 9

Near complete Resection 1 


\section{TreatMenT}

\section{Tamoxifen (TAM)}

Two weeks after surgery, patients were started on TAM per os $120 \mathrm{mg} / \mathrm{m}^{2}$ twice a day for three months, the last $2 \frac{1}{2}$ months of which TAM was given concurrently with RT.

\section{External beam radiotherapy (RT)}

RT was started two weeks from the date of starting TAM. RT was delivered by megavoltage equipment ranging from Cobalt60 up to $10 \mathrm{MV}$ photons. Patients were treated supine using a head immobilization device. The target volume (TV) was based on the preoperative CT/MRI. The initial TV included the contrast-enhancing lesion and surrounding edema plus a twocentimeter margin. The reduced volume included the contrastenhancing lesion, without edema, plus a $2 \frac{1}{2}$ centimeter margin. CT-based three-dimensional conformal planning was performed for all patients. Patients received $45 \mathrm{~Gy} / 25$ fractions/ $1.8 \mathrm{~Gy}$ daily to the initial volume and $14.4 \mathrm{~Gy} / 8$ fractions/1.8Gy daily to the reduced volume. One patient whose disease progressed after three weeks of high dose TAM was treated with an accelerated course of RT and received a final total dose of $35 \mathrm{~Gy} / 14$ fractions.

\section{Follow-up}

During treatment, all patients were assessed on a weekly basis by the radiation oncologist. The evaluation consisted of neurological examination, determination of KPS and assessment for any acute toxicity. Both acute and delayed toxicities were assessed according to RTOG scoring criteria. Imaging studies (contrast CTscan or MRI) were obtained at the end of two weeks of TAM, then monthly or at the time of neurological deterioration.

\section{Criteria for evaluation of therapy outcome}

All patients were consistently followed-up with the same diagnostic imaging study. CT or MRI studies assessed objective radiological tumor response, which was recorded according to MacDonald et al's ${ }^{14}$ response criteria for malignant gliomas.

Survival time and time to disease progression were measured from the date of surgery. Survival curves were calculated using the Kaplan-Meier method. ${ }^{15}$

\section{RESULTS}

\section{Complications of treatment}

TAM was usually well tolerated and patients' compliance to the high number of daily pills was excellent. One patient developed grade IV nausea and vomiting three weeks after start of TAM. TAM dose was then decreased to $100 \mathrm{mg} / \mathrm{m}^{2}$ twice a day. TAM was eventually stopped at two months because of persistent grade III nausea and vomiting despite dose reduction and appropriate anti-emetic medication. One other patient developed bilateral deep venous thrombosis (DVT) at $5 \frac{1}{2}$ weeks and TAM was stopped at that time. Grade I radiation dermatitis and localized alopecia limited to treatment portals occurred in all patients (Table 2). We did not observe any evidence of myelosuppression or cardiac toxicities.
Table 2: Side effects of Treatment

\begin{tabular}{lcl}
\hline Side Effects & Number of Patients & Grade \\
Nausea \& Vomiting & $1(8.3 \%)$ & III - IV \\
Deep Venous Thrombosis & $1(8.3 \%)$ & \\
Dermatitis \& Alopecia & $12(100 \%)$ & I
\end{tabular}

Table 3: Disease Progression

$\begin{array}{lcl}\text { Extent of surgery } & \begin{array}{c}\text { Time to Progression } \\ \text { (Median Time) }\end{array} & \text { Pattern of Failure } \\ \text { Biopsy } & 5.8 \mathrm{wks} & 1 \text { peripheral \& distant } \\ \text { Partial Resection } & 17.7 \mathrm{wks} & \begin{array}{l}5 \text { central } \\ 2 \text { peripheral } \\ 2 \text { distant }\end{array} \\ & & 1 \text { central } \\ \text { Gross Total Resection } & 22.4 \mathrm{wks} & \end{array}$

\section{Pattern of recurrence}

There were no radiological responses either after two weeks of TAM or at the end of RT. Based on clinical criteria of deteriorating KPS, functional neurological status, increased steroid requirements and sequential radiological studies, 11 of the 12 patients $(91.6 \%)$ were observed to have disease progression (Table 3). One other patient died from an acute abdomen. His autopsy report revealed bilateral pulmonary embolism and residual-recurrence of brain tumor in the left temporal region. The patient had been relatively well up to his death, and his last brain CT/MRI had not revealed any disease progression. Unfortunately, he was the only patient on whom we received an autopsy report.

Central recurrence, relapse at the primary tumour, was observed in six $(54.5 \%)$ patients, peripheral relapse, within one to two $\mathrm{cm}$ of the primary tumor, in two patients (18.1\%), distant relapse within the cerebral nervous system occurred in two patients (18.1\%), and both distant and peripheral recurrence occured in one patient $(9.1 \%)$.

\section{Survival analysis}

All patients were followed-up until death or to the date of last follow-up. The median follow- up time was 40 weeks (range $22-$ 84 weeks). The median time to progression was 17.7 weeks (range 5.1 - 43.8 weeks), (Figure 1). The median survival time was 33.4 weeks (range $10-79.7$ weeks), (Figure 2). Actuarial survival rates at 48 and 74 weeks was $40 \%$ and $15 \%$, respectively. When the patients were classified according to the RTOG RPA, the median survival time of class III-IV patients was 11.5 months (range 5.2-18 months) and it was 5.1 months (range 2.1-28.1 months) for class V-IV patients. 


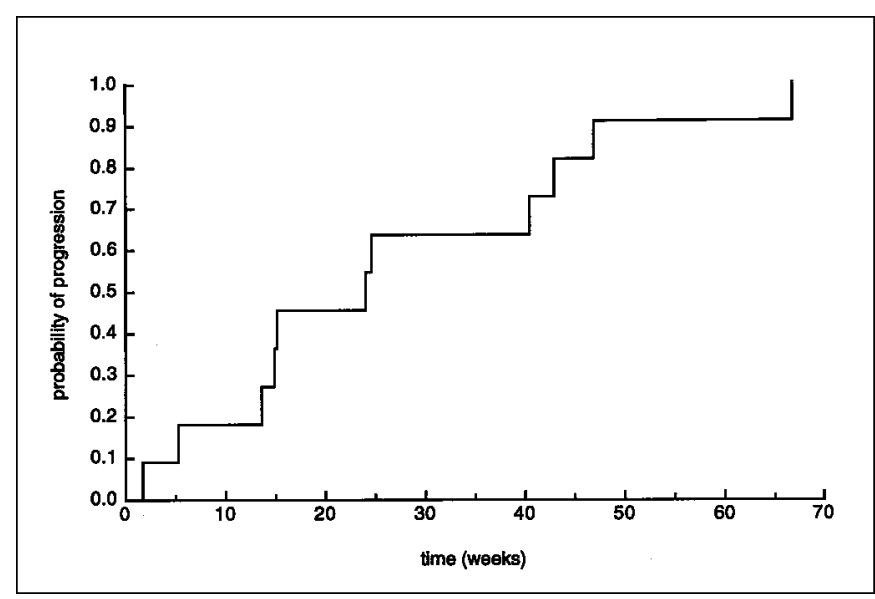

Figure 1: Time to Progression

\section{Treatment of recurrence}

Of the patients considered to have disease recurrence, four had supportive care and seven received postrecurrence therapy. These seven patients were treated with bichloronitrosurea and one of them had procarbazine, chloronitrosurea, visnristine after BCNU failure. One of the two patients who did not complete RT as planned was treated with bichloronitrosurea and stereotactic radiosurgery. The other one was treated with accelerated RT. The median survival time of the four patients who had supportive care only was 10 weeks (range 5.1-22.7 weeks) from the time of disease progression. The median survival time of the seven patients who had postrecurrence therapy was 22.4 weeks (range 13-43.8 weeks).

\section{Discussion}

TAM has been shown to inhibit growth of glial cell lines ${ }^{3}$ and has radiosensitizing properties. Several groups, including ours, have studied its role as salvage therapy in patients with recurrent GBM. These results indicated that high dose TAM was welltolerated. ${ }^{5,10,11}$ In a series of 30 patients with recurrent high-grade gliomas, we observed $20 \%$ partial response and $3 \%$ disease stabilization. ${ }^{5}$ The median duration for the partial responders was 33 weeks and the median survival was 24 weeks. These results stimulated us to embark on a phase IB trial of high dose TAM used in the adjuvant setting, together with brain RT for patients with GBM. In the present study, toxicity was limited to grade IV nausea and vomiting in only one patient (8.3\%). In fact this patient continued to have grade III nausea and vomiting even though TAM dose had been reduced to $100 \mathrm{mg} / \mathrm{m}^{2}$ and appropriate anti-emetic medication was given. Another patient (8.3\%) developed a DVT. It is not clear whether this complication is TAM related. In the National Surgical Adjuvant Breast and Bowel Project P-1 study, 13,388 women were randomized to receive $20 \mathrm{mg}$ per day of either TAM or placebo for five years. The TAM group $(n=6681)$ had $0.52 \%$ events of DVT whereas the placebo group $(n=6707)$ had $0.32 \%$ events of DVT. ${ }^{16}$ Furthermore, DVT is known to occur in $19 \%$ of patients with GBM. ${ }^{17}$ We did not observe any evidence of

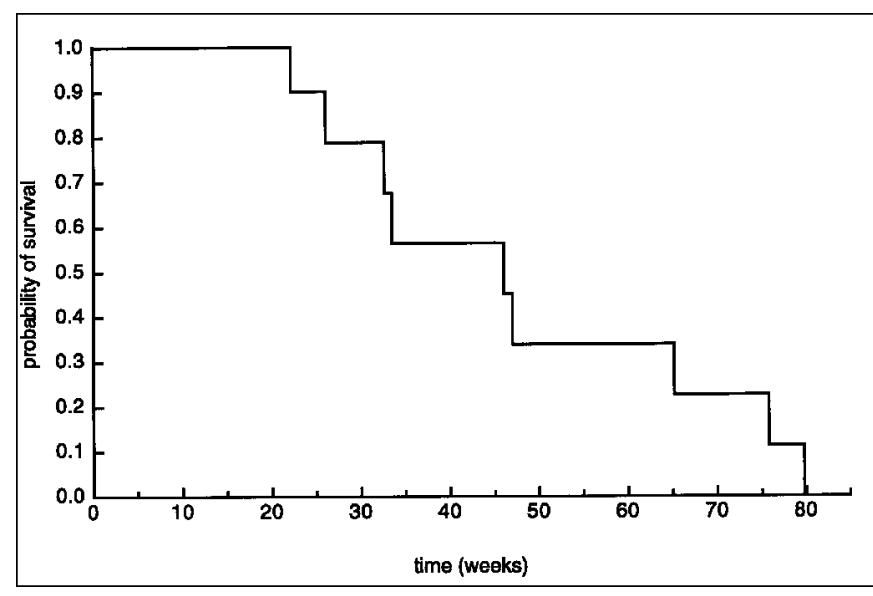

Figure 2: Overall Survival

myelosuppression, cardiac arrhythmias, or retinopathies. Chamberlain et al, ${ }^{10}$ Couldwell et al, ${ }^{11}$ and Brandes et al ${ }^{18}$ reported toxicity levels comparable to ours, whereas Chang et $\mathrm{al}^{19}$ reported an early closure of their phase II trial combining interferon alpha and high dose TAM because of significant neurotoxicity manifested by dizziness and unsteady gait in patients with recurrent GBM. These authors used doses of TAM ranging from $100 \mathrm{mg} /$ day to $100 \mathrm{mg}$ BID. Although not a primary end point in our study, the median survival time of our RTOG RPA classes III-IV (11.5 months) and RPA classes V-VI (5.1 months) were comparable with their corresponding RTOG RPA classes. ${ }^{13}$

In conclusion, this phase I study demonstrates the feasibility of adjuvant high dose TAM in combination with postoperative conventional RT. This therapeutic regimen is relatively welltolerated and is not associated with any significant increase in radiation-induced neurological toxicity. However no patient responded to this approach and there appears to be no improvement in survival or pattern of failure, suggesting that high dose TAM might not bring any benefit in the adjuvant setting for patients with glioblastoma multiforme.

\section{REFERENCES}

1. Leibel SA, Scott CB, Loeffler JS. Contemporary approaches to the treatment of malignant gliomas with radiation therapy. Sem Oncol 1994; 21:198-219.

2. Devita VT, Hellman S, Rosenberg SA. Cancer Principles and Practice of Oncology. 5th Ed Lippincott-Raven, 1997: 2023.

3. Pollack IF, Randall MS, Kristofik MP, et al. Effects of tamoxifen on DNAsynthesis and proliferation of human malignant glioma line in vitro. Cancer Res 1990; 50:7134-7138.

4. O'Brian CA, Liskamp RM, Solomon DH, et al. Inhibition of protein kinase-c by tamoxifen. Cancer Res 1985; 45:2462-2465.

5. Baltuch G, Shenouda G, et al. High dose tamoxifen in the treatment of recurrent high-grade glioma: a report of clinical stabilisation and tumor regression. Can J Neurol Sci 1993; 20:168-170.

6. Shenouda G, Labataya M. Growth inhibition of human glioma cell lines by tamoxifen. Unpublished data.

7. Hansen SB, Galsgord H, et al. Tamoxifen for brain metastases from breast cancer. Ann Neurol 1986;20:544-547.

8. Berd D, Mc Laughlin CJ, et al. Short course of high dose tamoxifen with cytotoxic chemotherapy for metastatic melanoma. 
Proceedings of ASCO, 1991:10:291.

9. Zhang W, Yamada $\mathrm{H}$, et al. Enhancement of radiosensitivity by tamoxifen in C6 glioma cells. Neurosurgery 1992; 31:725-730.

10. Chamberlain MC, Kormanik PA. Salvage chemotherapy with tamoxifen for recurrent anaplastic astrocytomas. Arch Neurol 1999; 56: 703-708.

11. Couldwell WT, Hinton DR, et al. Treatment of recurrent malignant gliomas with chronic oral high dose tamoxifen. Clin Cancer Res 1996; 2: 619-622.

12. Shenouda G, Souhami L, et al. Radiosurgery and accelerated radiotherapy for patients with glioblastoma. Can J Neurol Sci 1997; 24: 110-115.

13. Curran WJ, Scott CB, et al. Recursive partitioning analysis of prognostic factors in three Radiation Therapy Oncology Group malignant glioma trials. J Natl Cancer Inst 1993; 85:704-710.

14. Mac Donald DR, Cascino TL, et al. Response criteria for phase II studies of supratentorial malignant glioma. J Clin Oncol 1990; 8: $1277-1280$.

15. Kaplan EL, Meier P. Nonparametrics estimation for incomplete observations. J Am Stat Assoc 1958; 53: 457-481.

16. Fisher B, Costantino JP, et al. Tamoxifen for prevention of breast cancer: report of the NSABPP-1 study. J Natl Cancer Inst 1998; 90: 1371-1388.

17. Cheruku R, Tapazoglou E, et al. The incidence and significance of thromboembolic complications in patients with high-grade gliomas. Cancer 1991; 68:2621-2624.

18. Brandes AA, Ermani $M$, et al. Procarbazine and high dose tamoxifen as a second line regimen in recurrent high-grade gliomas: a phase II study. J Clin Oncol 1999; 17:645-650.

19. Chang SM, Baker FG, et al. High dose oral tamoxifen and subcutaneous interferon alpha-2a for recurrent glioma. J Neurooncol 1998; 37:169-176. 